\title{
Effects of a Multidisciplinary Intervention on the Presence of Neuropsychiatric Symptoms and Psychotropic Drug Use in Nursing Home Residents WithYoung-Onset Dementia
}

Citation for published version (APA):

Appelhof, B., Bakker, C., de Vugt, M. E., van Duinen-van den IJssel, J. C. L., Zwijsen, S. A., Smalbrugge, M., Teerenstra, S., Verhey, F. R. J., Zuidema, S. U., \& Koopmans, R. T. C. M. (2019). Effects of a Multidisciplinary Intervention on the Presence of Neuropsychiatric Symptoms and Psychotropic Drug Use in Nursing Home Residents WithYoung-Onset Dementia: Behavior and Evolution of Young-Onset Dementia Part 2 (BEYOND-II) Study. American Journal of Geriatric Psychiatry, 27(6), 581-589. https://doi.org/10.1016/j.jagp.2018.12.032

Document status and date:

Published: 01/06/2019

DOI:

10.1016/j.jagp.2018.12.032

Document Version:

Publisher's PDF, also known as Version of record

\section{Document license:}

Taverne

\section{Please check the document version of this publication:}

- A submitted manuscript is the version of the article upon submission and before peer-review. There can be important differences between the submitted version and the official published version of record. People interested in the research are advised to contact the author for the final version of the publication, or visit the DOI to the publisher's website.

- The final author version and the galley proof are versions of the publication after peer review.

- The final published version features the final layout of the paper including the volume, issue and page numbers.

Link to publication

\footnotetext{
General rights rights.

- You may freely distribute the URL identifying the publication in the public portal. please follow below link for the End User Agreement:

www.umlib.nl/taverne-license

Take down policy

If you believe that this document breaches copyright please contact us at:

repository@maastrichtuniversity.nl

providing details and we will investigate your claim.
}

Copyright and moral rights for the publications made accessible in the public portal are retained by the authors and/or other copyright owners and it is a condition of accessing publications that users recognise and abide by the legal requirements associated with these

- Users may download and print one copy of any publication from the public portal for the purpose of private study or research.

- You may not further distribute the material or use it for any profit-making activity or commercial gain

If the publication is distributed under the terms of Article $25 \mathrm{fa}$ of the Dutch Copyright Act, indicated by the "Taverne" license above, 
Regular Research Article

\section{Effects of a Multidisciplinary}

Intervention on the Presence of

Neuropsychiatric Symptoms and

Psychotropic Drug Use in Nursing

Home Residents WithYoung-Onset

Dementia: Behavior and Evolution

of Young-Onset Dementia Part 2

(BEYOND-II) Study

Britt Appelhof, M.Sc., Christian Bakker, M.Sc., Ph.D., Marjolein E. de Vugt, M.Sc., Ph.D.,

Jeannette C.L. van Duinen-van den IJssel, M.Sc., Sandra A. Zwijsen, M.Sc., Ph.D., Martin Smalbrugge, M.D., Ph.D., Steven Teerenstra, M.Sc., Ph.D., Frans R.J. Verbey, M.D., Ph.D., Sytse U. Zuidema, M.D., Ph.D., Raymond T.C.M. Koopmans, M.D., Ph.D.

\section{ARTICLE I N F O}

Article bistory:

Received October, 252018

Revised December, 302018

Accepted December, 312018

\begin{abstract}
A B S T RA C T
Objective: The effect of an intervention on neuropsychiatric symptoms (NPS), particularly agitation and aggression, and psychotropic drug use (PDU) in institutionalized people with young-onset dementia (YOD) was evaluated. Methods: A randomized controlled trial was conducted using a stepped wedge design. Thirteen YOD special care units were randomly assigned to three
\end{abstract}

From the Department of Primary and Community Care (BA, CB, JCLD, RTCMK), Radboud Institute for Health Sciences, Radboud University Medical Center, Nijmegen, The Netherlands; Knowledge Center for Specialized Care (BA), Landrijt Archipel, Eindhoven, The Netherlands; Radboudumc Alzheimer Center (BA, CB, JCLD, RTCMK), Nijmegen, The Netherlands; Center for Specialized Care in Young-Onset Dementia (CB), Florence Mariahoeve, The Hague; Alzheimer Center Limburg (MEV, FRJV), School for Mental Health and Neuroscience, Maastricht University Medical Center, Maastricht, The Netherlands; Department of General Practice and Elderly Care Medicine/Amsterdam Public Health Research Institute (SAZ, MS), VU University Medical Center, Amsterdam; Department of Health Evidence (ST), Section Biostatistics, Radboud Institute for Health Sciences, Radboud University Medical Center, Nijmegen, The Netherlands; Department of General Practice and Elderly Care Medicine (SUZ), University Medical Center Groningen, Groningen, The Netherlands; De Waalboog "Joachim en Anna" Center for Specialized Geriatric Care (RTCMK), Nijmegen, The Netherlands; and the Send correspondence and reprint requests to Britt Appelhof, M.Sc., Department of Primary and Community Care, Radboud University Medical Center, P.O. Box 9101, 6500 HB Nijmegen, The Netherlands.. e-mail: britt.appelhof@radboudumc.nl

(c) 2019 American Association for Geriatric Psychiatry. Published by Elsevier Inc. All rights reserved.

https: / / doi.org/10.1016/j.jagp.2018.12.032 
Key Words:

Young-onset dementia nursing home

neuropsychiatric symptoms aggression

psychotropic drug use intervention groups, which received the intervention at different time points. Four assessments took place every 6 months during a period of 18 months. Two bundred seventy-four people with YOD who resided in YOD special care units participated, of whom 131 took part in all assessments. The intervention consisted of an educational program combined with a care program, which structured the multidisciplinary process of managing NPS. The care program included the following five steps: evaluation of psychotropic drug prescription, detection, analysis, treatment, and evaluation of treatment of NPS. The Coben-Mansfield Agitation Inventory and the Neuropsychiatric Inventory-Nursing Home version were used to assess NPS. Data on PDU were retrieved from residents' medical files. Multilevel models were used to evaluate the effect of the intervention, which accounted for clustering of measurements in clients within units. Results: No significant differences were found in agitation, aggression, otber NPS, or PDU after crossing over to the intervention condition. Conclusion: We found no evidence that the intervention for management of NPS in nursing bome residents with YOD was more effective in reducing agitation, aggression, other NPS, or PDU compared with care as usual. (Am J Geriatr Psychiatry 2019; 27:581-589)

\section{INTRODUCTION}

W hen dementia occurs before the age of 65 , this is most commonly referred to as young-onset dementia (YOD). Of the nursing home (NH) residents with YOD, 90\% show one or more neuropsychiatric symptoms (NPS). ${ }^{1}$ These high rates are troublesome given the serious negative health outcomes associated with NPS in dementia, such as loss of quality of life of the $\mathrm{NH}$ resident, high workload and distress of professional caregivers, and increased costs of care. ${ }^{2-7}$ Comorbidity is less common in people with youngonset Alzheimer disease than in people with lateonset Alzheimer disease, suggesting that people with YOD are less frail. ${ }^{8}$ As a consequence, NPS in YOD might be more severe compared with late-onset dementia (LOD) because of increased physical fitness, such as walking speed and strength. Indeed, a recent study by van Duinen-van den IJssel et al. ${ }^{7}$ showed that $\mathrm{NH}$ staff caring for people with YOD experience more distress related to NPS compared with NH staff caring for people with LOD. Psychotropic drug use (PDU) is common in the management of NPS in NH residents with LOD and YOD. ${ }^{9,10}$ PDU is associated with poor health outcomes, such as stroke, increased mortality, and reduced quality of life. ${ }^{3,11,12}$ However, between $76.9 \%$ and $87.6 \%$ of $\mathrm{NH}$ residents with YOD use one or more psychotropic drugs. ${ }^{4,9}$ Those rates are higher compared with PDU in $\mathrm{NH}$ residents with LOD. ${ }^{9}$

The high prevalence rates of NPS and PDU stress the need for the development and evaluation of nonpharmacologic interventions in YOD. To successfully manage NPS, many models emphasize that the underlying causes of NPS need to be identified and treated. ${ }^{13}$ One of these models is the unmet needs framework, in which NPS are perceived as behaviors through which the person with dementia might indirectly communicate an underlying need. ${ }^{13}$ Needs can be medical (e.g., physical illness, pain, and mobility), psychosocial (e.g., life habits and premorbid personality), or environmental (e.g. under/overstimulation and behavior of $\mathrm{NH}$ staff/other residents). ${ }^{14,15}$ People with YOD have specific age-related care needs regarding daytime activities, social interaction, intimate relationships, and information that are often unmet. ${ }^{16}$ With knowledge of the underlying causes of NPS, an intervention can be individualized to the specific needs of residents instead of suppressing behavior with the use of psychotropic drugs, concealing behavior through which the person with dementia might indirectly communicate an underlying need. ${ }^{14,17,18}$

In the current study, the effect of a multidisciplinary intervention for the management of NPS in NH residents with YOD was evaluated. ${ }^{19,20}$ The intervention was based on the "Grip on Challenging 
Behavior" care program that has been effective in the management of NPS in LOD. ${ }^{19-22}$ The aims of the study are to 1) evaluate the effect of the intervention on the prevalence of NPS, particularly agitation and aggression, compared with care as usual; and 2) evaluate the effect of the intervention on PDU.

\section{METHODS}

This cluster randomized controlled trial is part of the Behavior and Evolution of Young-Onset Dementia Part 2 (BEYOND-II) study. ${ }^{23}$ Process data were assessed to be able to interpret the outcomes of this randomized controlled trial. ${ }^{24}$ The process data showed sufficient internal and external validity, allowing for further effect analyses. ${ }^{24,25}$

\section{Setting and Subjects}

In this study, 13 YOD special care units (SCUs) units delivering specialized treatment and support for people with YOD-participated. ${ }^{24}$ The YOD SCUs were recruited through NHs affiliated with the Dutch YOD Knowledge Center. Residents with a dementia diagnosis with a symptom onset before the age of 65 who resided on the YOD SCU for at least 1 month were eligible for inclusion in the study. The exclusion criteria were lack of informed consent provided by the legal representative and dementia caused by human immunodeficiency virus, traumatic brain injury, Down syndrome, Korsakoff syndrome, or Huntington disease. Diagnoses of dementia subtypes were made before inclusion according to internationally accepted criteria for diagnosing dementia subtypes and were retrieved from medical files. ${ }^{26-31}$ Newly admitted residents were recruited at the end of the study, replacing deceased residents and residents who moved to another care unit during the study.

\section{Intervention}

The development of the intervention "Grip on NPS in Institutionalized People with YOD" is described in detail by Zwijsen et al. ${ }^{20}$ To increase implementation, the $\mathrm{NH}$ staff received an educational program that consisted of two training sessions (2.5 and 1.5 hours). In the educational program, causes and mechanisms of NPS were discussed with the NH staff, and the use and relevance of the care program were explained. After receiving the educational program, the care program on the management of NPS was implemented (Fig. 1). The care program provided guidance for the multidisciplinary team involved in the management of NPS in Dutch NHs to structure the process of detection, analysis, treatment, and evaluation of NPS. This care program consisted of five steps, which were consecutive and formed a cycle, except for the evaluation of appropriateness of psychotropic drug prescription. This separate step was a tool for the evaluation of appropriateness of psychotropic drug prescription by the elderly care physician. ${ }^{32,33}$ The tool was performed for all residents (with or without NPS) in the first 2 months after the SCU was enrolled in the intervention condition. After the initial screening, the tool was used at the physician's own discretion. The other four consecutive steps of the care program had a circular structure (Fig. 1).

Detection of NPS occurred through usual observations of the multidisciplinary team or with the systematic use of a screening tool every 6 months by a vocational nurse. When NPS were detected, a structured analysis of possible causes of the NPS observed was conducted by the (vocational) nurse. This analysis included a tool for the detection of unmet needs possibly underling the NPS. ${ }^{34}$ When necessary, the elderly care physician and/or the psychologist continued the analysis. After this analysis, treatment options were discussed within the multidisciplinary team, and a treatment plan was established by the elderly care physician and/or the psychologist. The care program did not prescribe a specific intervention. The choice of intervention relied on the hypothesized causes of the NPS, the preferences of the resident, and the available options in the NH. However, psychosocial treatments were preferred, with PDU only if other treatments had little or no effect. The treatment outcomes were evaluated by the multidisciplinary team, and if unsatisfactory, other treatments were considered or the analysis performed again. All tools of the care program were fully digitized and contained automatic reminders.

\section{Design}

To evaluate the effect of the intervention, a stepped wedge design was used (Table 1). This design allowed the YOD SCUs to cross over from the control 
FIGURE 1. The five steps of the care program "Grip on NPS in institutionalized people with YOD." ${ }^{23}$ Reprinted with permission. PD: psychotropic drugs. NPS: neuropsychiatric symptoms.

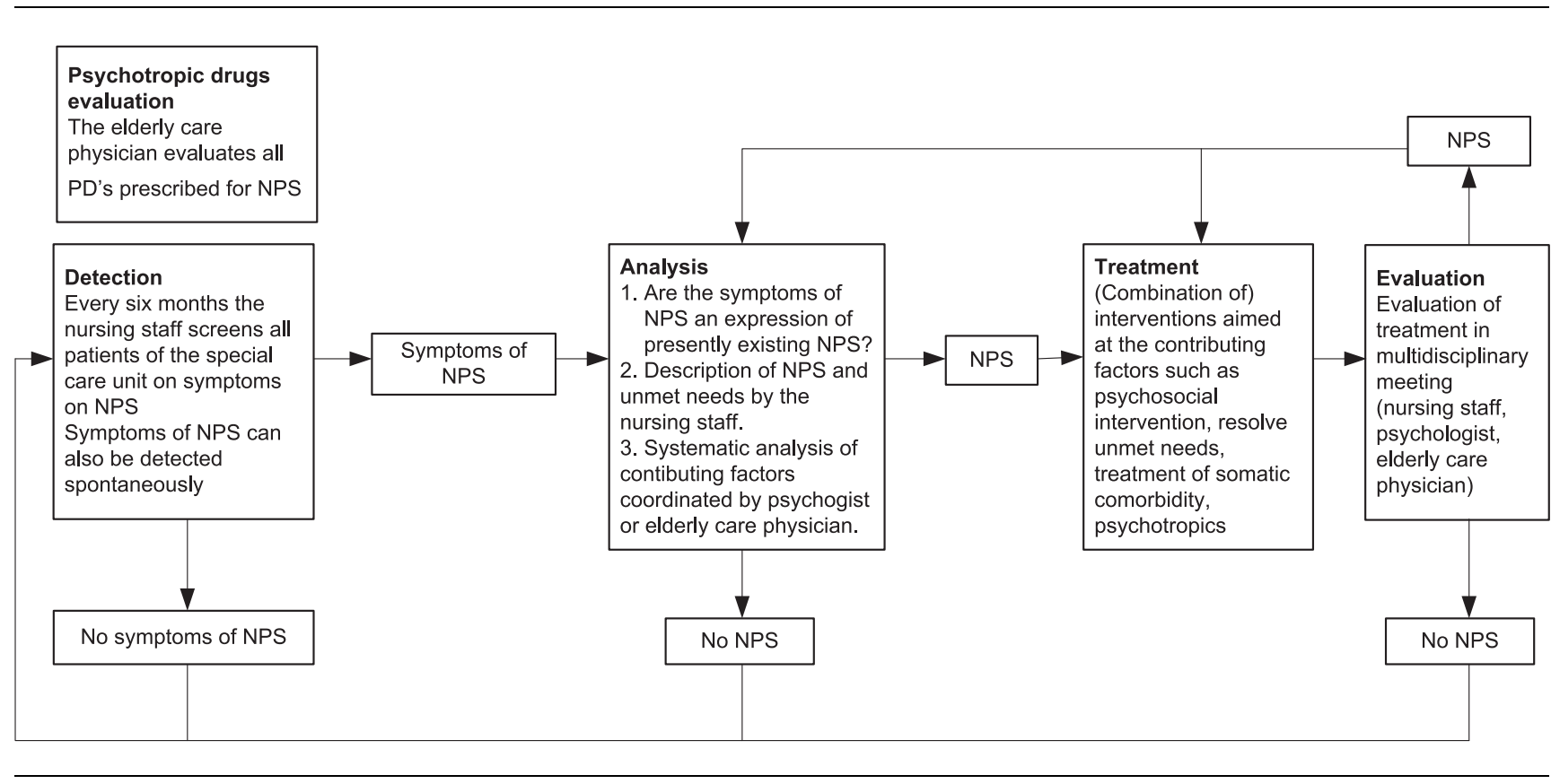

to the intervention condition over time, assuring that all YOD SCUs received the intervention. ${ }^{35}$ The 13 YOD SCUs were randomly assigned to 3 groups. Every 6 months, a new group entered the intervention condition. The control condition consisted of care as usual, without the educational program and use of the care program. Four assessments took place every 6 months during a period of 18 months (September 2015 to April 2017).

\section{Data Collection and Ethical Considerations}

The BEYOND-II study protocol was approved by the Medical Ethics Committee region Arnhem/Nijmegen

\section{TABLE 1. Stepped Wedge Design}

\begin{tabular}{llll}
\hline & Group 1 & Group 2 & Group 3 \\
\hline T0 & $0^{\mathrm{a}}$ & 0 & 0 \\
T1 & $1^{\mathrm{b}}$ & 0 & 0 \\
T2 & 1 & 1 & 0 \\
T3 & 1 & 1 & 1
\end{tabular}

Notes: Reprinted with permission. ${ }^{23}$ There are four twice yearly assessments, and each group consists of four or five YOD SCUs. T0: assessment 0 ; T1: assessment 1; T2: assessment 2; T3: assessment 3 .

${ }^{\mathrm{a}} 0=$ control condition.

${ }^{\mathrm{b}} 1=$ intervention condition. (file number 2015-1558) and registered in the Dutch Trial Register (ID NTR5018). This research project was conducted according to the principles of the Declaration of Helsinki, version November 2013 (www.wma.net), and in agreement with the laws regarding medical-scientific research in humans.

Written informed consent was obtained from the legal representative of each resident. After receiving informed consent, trained researchers and research assistants collected data from the residents' medical files and through structured interviews with nursing staff.

\section{Primary Outcome}

The Dutch version of the Cohen-Mansfield Agitation Inventory was used to assess agitation and aggression. ${ }^{14,36}$ The Cohen-Mansfield Agitation Inventory (CMAI) has a well-established validity and reliability and assesses 29 agitated or aggressive behaviors. ${ }^{36}$ The frequency of each symptom is rated on a sevenpoint frequency scale (range: $1-7$ ), ranging from never to several times an hour. We used CMAI factors based on a previous study of LOD in which three factors in a large $\mathrm{NH}$ sample were found: 
physically nonaggressive behaviors (range: 7-49), physically aggressive behaviors (range: $8-56$ ), and verbally agitated behaviors (range: $4-28){ }^{37}$

\section{Secondary Outcomes}

To determine effects of the care program on other NPS, the Dutch version of the Neuropsychiatric Inventory-Nursing Home version (NPI-NH) was used. The NPI-NH has a high inter-rater reliability and is found to be a valid instrument for the assessment of a wide range of NPS in dementia. ${ }^{38}$ The NPI-NH measures 12 neuropsychiatric symptoms: delusions, hallucinations, agitation/aggression, depression, anxiety, euphoria, apathy, disinhibition, irritability, aberrant motor behavior, nighttime behavior disturbances, and eating disturbances. For each symptom, a screening question is used to determine whether the symptom is present. If the symptom is present, frequency (F) and severity (S) are rated on fourpoint (range: $1-4$ ) and three-point (range: $1-3$ ) Likert scales, respectively, for each symptom. Scores for each symptom are calculated as $\mathrm{F} \times \mathrm{S}$ (range: 1-12). A symptom score of at least four is considered clinically relevant. ${ }^{39}$

PDU was derived from the NHs' pharmacists' electronic files and was classified according to the Anatomical Therapeutic Chemical classification system as antipsychotics, anxiolytics, hypnotics, antidepressants, antiepileptics, antidementia drugs, and any psychotropic medication. ${ }^{40}$ As needed medications, which are medications not taken according to a fixed schedule but given only in the prescribed dosage if needed, were not included because it was unclear if and how often these drugs were actually used. Furthermore, antiepileptics used by residents with epilepsy were not registered as PDU.

\section{Other Measurements}

Medical and demographic data were extracted from the residents' medical files. Data on dementia subtype, age, sex, length of stay at the SCU, and date of inclusion were recorded. Dementia severity was assessed with the Global Deterioration Scale (GDS). ${ }^{41}$ The GDS describes seven different stages of dementia on a seven-point scale (range: 1-7), ranging from "subjectively and objectively normal cognition" to "severe cognitive decline."
Process data showed that the fidelity of the intervention differed between SCUs. ${ }^{24}$ Therefore, fidelity was conceptualized into an implementation score consisting of three components. A score was calculated for the step detection based on the number of times the step was completed with regard to the number of residents residing on the SCU (score of two if used at least once every 6 months for $75 \%-100 \%$ of all residents, score of one if used for $50 \%-74 \%$, and score of zero if used in $<50 \%) .{ }^{24}$ In addition, the $\mathrm{NH}$ staff rated the percentages of cases with challenging behavior on which they worked according to the care program on a questionnaire (score of two if used in $75 \%-100 \%$ of cases, score of one if used in $50 \%-74 \%$, and score of zero if used in $<50 \%$ ). Finally, two authors closely involved in the implementation (JCLD and BA) separately rated it based on their communication with the SCUs about its progress (range: $0-2)$. Disagreements were resolved by discussion. The scores on the three components were summed, resulting in a total implementation score (range: 0-6).

\section{Statistical Analysis}

All analyses were performed using SPSS 22 (IBM, Armonk, NY). Demographic variables of the NH residents at the time of enrollment in the study were described by means or proportions.

Multilevel model analyses were used to adjust for the clustering of residents in the 13 different SCUs (random effect for SCU) and the correlation of the repeated measures within the residents (random effect for resident, nested within SCU). Time and interaction of time with treatment were included as a fixed effect to model time trend (in absence of treatment) and the effect of treatment, respectively. Multilevel models were fitted with the restricted maximum likelihood method, and the 95\% confidence intervals and $\mathrm{p}$ values of the coefficients in the model were based on Wald tests and $t$ distributions, with Satterthwaite approximation of $\mathrm{df}$. The 12 symptom scores on the NPI-NH were dichotomized into clinically relevant symptoms (symptom score: $\geq 4$ ) or no clinically relevant symptoms (symptom score: $<4$ ). Data on PDU were also dichotomized (present or absent) for each category. In case of binary variables, the fit for logistic and linear mixed model logistic regression was compared by comparing the observed and predicted profiles of SCUs over time. In the case 
of an equal or better fit, we used linear regression instead of logistic regression, as this allows direct interpretation in terms of change of percentage over time.

In a previous study evaluating the effect of the intervention on LOD, dementia severity and time being exposed to the intervention had an influence on the intervention effect. ${ }^{21}$ In addition, differences in fidelity between SCUs could influence the intervention effect. ${ }^{24}$ Therefore, to investigate whether the intervention effect was different for residents with more advanced dementia (GDS score $<5$ mild, score $=5$ moderate, or score $\geq 6$ severe) or residents exposed to the intervention for a longer period of time (0-6 months, $6-12$ months, or $12-18$ months), or for higher fidelity (implementation score), interaction effects between the intervention and these variables were investigated. In all analyses, a $p$ value $<0.05$ was considered statistically significant.

\section{RESULTS}

In total, $274 \mathrm{NH}$ residents with YOD participated in this study. Table 2 provides demographic and clinical characteristics of the $\mathrm{NH}$ residents at time of

TABLE 2. Demographic and Clinical Characteristics of Nursing Home Residents at Time of Inclusion

\begin{tabular}{|c|c|c|}
\hline & n (\%) & $\begin{array}{l}\text { Mean (SD) } \\
\text { [Range] }\end{array}$ \\
\hline Age & & $\begin{array}{l}63.86(5.91) \\
{[39-78]}\end{array}$ \\
\hline Sex (male) & $138(50.4)$ & \\
\hline Length of stay at SCU (months) ${ }^{\mathrm{a}}$ & & $\begin{array}{l}28.65(32.10) \\
{[1-259]}\end{array}$ \\
\hline \multicolumn{3}{|l|}{ Dementia severity (GDS) ${ }^{\mathrm{b}}$} \\
\hline Mild $(2,3,4)$ & $43(15.7)$ & \\
\hline Moderate (5) & $57(20.8)$ & \\
\hline Severe $(6,7)$ & $172(62.8)$ & \\
\hline \multicolumn{3}{|l|}{ Dementia subtype } \\
\hline Alzheimer disease & $120(43.8)$ & \\
\hline Vascular dementia & $29(10.6)$ & \\
\hline Frontotemporal dementia & $80(29.2)$ & \\
\hline \multicolumn{3}{|l|}{ Mixed } \\
\hline Alzheimer's/vascular & $14(5.1)$ & \\
\hline Lewy body/Parkinson's & $5(1.8)$ & \\
\hline Alcohol-related dementia & $6(2.2)$ & \\
\hline Other & $20(7.3)$ & \\
\hline \multicolumn{3}{|c|}{$\begin{array}{l}\text { Notes: } \mathrm{n}=274 . \text { SD: standard deviation. } \\
\text { a } 1 \text { missing. } \\
\text { b } 5 \text { missing }\end{array}$} \\
\hline
\end{tabular}

TABLE 3. Baseline Data on Outcome Variables at Time of Inclusion

\begin{tabular}{lll}
\hline & n (\%) & Mean (SD) \\
\hline CMAI factor scores & & \\
Physically aggressive behaviors & & $13.02(6.41)$ \\
Physically nonaggressive behaviors & & $14.86(7.90)$ \\
Verbally agitated behaviors & & $8.46(5.90)$ \\
Clinically relevant NPI-NH & & Mean F $\times \mathrm{S}^{\mathrm{a}}(\mathrm{SD})$ \\
Delusions & $29(12.8)$ & $8.45(2.87)$ \\
Hallucinations & $29(12.8)$ & $6.86(3.01)$ \\
Agitation/aggression & $95(41.9)$ & $7.27(2.80)$ \\
Depression & $42(18.5)$ & $7.29(3.08)$ \\
Anxiety & $33(14.5)$ & $8.18(3.02)$ \\
Euphoria & $23(10.1)$ & $8.04(3.14)$ \\
Apathy & $93(41.0)$ & $8.52(3.28)$ \\
Disinhibition & $69(30.4)$ & $8.07(3.00)$ \\
Irritability & $84(37.0)$ & $7.63(2.63)$ \\
Aberrant motor behavior & $89(39.2)$ & $8.47(3.30)$ \\
Nighttime behavior disturbances & $37(16.3)$ & $7.57(2.97)$ \\
Eating disturbances & $43(18.9)$ & $7.56(2.86)$ \\
PDU Antipsychotics & & \\
Anxiolytics & $71(31.3)$ & \\
Hypnotics & $60(26.4)$ & \\
Antidepressants & $34(15.0)$ & \\
Antiepileptics & $80(35.2)$ & \\
Antidementia drugs & $22(9.7)$ & \\
Any psychotropic medication & $12(5.3)$ & \\
& $152(67.0)$ & \\
\hline
\end{tabular}

Notes: $\mathrm{n}=227$; only scores for residents included at $\mathrm{T} 0$, $\mathrm{T} 1$, or $\mathrm{T} 2$ who had not yet been exposed to the intervention are shown. SD: standard deviation.

${ }^{\mathrm{a}}$ Mean $\mathrm{F} \times \mathrm{S}=$ mean frequency $\times$ severity scores of clinically relevant NPI-NH scores.

inclusion. Seventy-six residents were lost to followup because they moved to another care unit or died before the end of the study. Sixty-seven newly admitted residents were included after T0. Baseline data on outcome variables are presented in Table 3.

For all variables (including binary variables), linear multilevel regression models were used because these models had a better or equally good fit and, in case of binary variables, were consistent with the logistic multilevel models in terms of the predicted percentage in each of the institutions at each of the time points or better. In the face of this consistency, we chose the linear mixed model, as this has an easier interpretation of absolute difference in percentages. The analyses showed no significant effect of the intervention on physically aggressive behaviors (estimate: 0.495; $\mathrm{p}=0.303$ ), physically nonaggressive behaviors (estimate: $-0.137 ; \mathrm{p}=0.825)$, or verbally agitated behaviors (estimate: -0.176 ; $\mathrm{p}=0.697$ ) (Table 4). Additionally, no effect of the intervention on other NPS or PDU was found (Table 4). 
TABLE 4. Effects of Intervention on NPS and PDU

\begin{tabular}{|c|c|c|c|c|}
\hline & \multirow[b]{2}{*}{ Estimate } & \multirow[b]{2}{*}{$\mathbf{p}$} & \multicolumn{2}{|c|}{$95 \% \mathrm{CI}$} \\
\hline & & & Lower Bound & Upper Bound \\
\hline \multicolumn{5}{|l|}{ CMAI Factor Scores } \\
\hline Physically nonaggressive behaviors & -0.137 & 0.825 & -1.358 & 1.074 \\
\hline Physically aggressive behaviors & 0.495 & 0.303 & -0.448 & 1.438 \\
\hline Verbally agitated behaviors & -0.176 & 0.697 & -1.065 & 0.713 \\
\hline \multicolumn{5}{|l|}{ Clinically Relevant NPI-NH } \\
\hline Delusions & -0.048 & 0.136 & -0.111 & 0.015 \\
\hline Hallucinations & 0.044 & 0.135 & -0.014 & 0.101 \\
\hline Agitation/aggression & -0.001 & 0.975 & -0.090 & 0.087 \\
\hline Depression & 0.022 & 0.560 & -0.052 & 0.096 \\
\hline Anxiety & 0.034 & 0.318 & -0.033 & 0.102 \\
\hline Euphoria & 0.031 & 0.338 & -0.033 & 0.095 \\
\hline Apathy & 0.051 & 0.320 & -0.051 & 0.154 \\
\hline Disinhibition & 0.077 & 0.092 & -0.013 & 0.167 \\
\hline Irritability & 0.000 & 0.999 & -0.087 & 0.087 \\
\hline Aberrant motor behavior & 0.049 & 0.284 & -0.041 & 0.139 \\
\hline Nighttime behavior disturbances & 0.050 & 0.180 & -0.023 & 0.122 \\
\hline Eating disturbances & 0.044 & 0.253 & -0.031 & 0.118 \\
\hline \multicolumn{5}{|l|}{ PDU } \\
\hline Antipsychotics & -0.002 & 0.956 & -0.064 & 0.060 \\
\hline Anxiolytics & -0.033 & 0.301 & -0.095 & 0.029 \\
\hline Hypnotics & -0.021 & 0.459 & -0.078 & 0.035 \\
\hline Antidepressants & -0.057 & 0.066 & -0.117 & 0.004 \\
\hline Antiepileptics & 0.029 & 0.126 & -0.008 & 0.067 \\
\hline Antidementia drugs & -0.005 & 0.781 & -0.045 & 0.044 \\
\hline Any psychotropic medication & -0.023 & 0.505 & -0.090 & 0.044 \\
\hline
\end{tabular}

Notes: Estimate (i.e., regression coefficient) from multilevel model analyses with random effect for SCU and random effect for resident nested within SCU. The $\mathrm{p}$ values and 95\% CIs were based on Wald tests and $t$ distributions, with Satterthwaite approximation of df. CI: confidence interval.

No significant interaction effects between dementia severity and fidelity and the intervention effect were found. With regard to the prevalence of delusions, a significant interaction effect for the effect of the intervention and the time a resident was exposed to the intervention was found $(p=0.024)$. After being exposed for a longer period of time to the intervention, it became more effective in decreasing delusions, with an estimated intervention effect of -0.06 $(\mathrm{p}=0.056)$ for SCUs that worked 0-6 months with the intervention to $-0.06+2 \times-0.06$ (estimated intervention effect: $-0.18 ; \mathrm{p}=0.08$ ) for SCUs that worked 12-18 months with the intervention.

\section{DISCUSSION}

To our knowledge, this is the first study to evaluate the effects of a multidisciplinary intervention on the management of NPS, particularly agitation and aggression, and PDU in NH residents with YOD. We found no evidence that the intervention was more effective in reducing agitation, aggression, other NPS, or PDU compared with care as usual.

An intervention for the management of NPS and PDU in LOD, on which our intervention was based, was able to diminish NPS and PDU. ${ }^{21}$ An explanation for the differences in effects between the original intervention and the adapted intervention for YOD might be that all participating SCUs in our study were recruited through $\mathrm{NHs}$ that were affiliated with the Dutch YOD Knowledge Center. Only care organizations offering specialized care for people with YOD are affiliated with the center. Therefore, they might had already (to some degree) developed effective working methods for the management of NPS in YOD before implementation of our intervention. Indeed, the process evaluation revealed that $\mathrm{NH}$ staff experienced overlap between the intervention and their current working methods. ${ }^{24}$ In addition, although most NH staff were satisfied with the overall content of the care program, some steps of the intervention (like the detection tool for monitoring PDU) were often rated as irrelevant. ${ }^{24}$ This suggests 


\section{Effects of a Multidisciplinary Intervention on the Presence of Neuropsychiatric}

that users of the intervention did not expect that these steps would be more effective in diminishing NPS and PDU than care as usual in YOD SCUs. In YOD SCUs, there was possibly less need for an intervention that structured the management of NPS compared with LOD care units. The needs of one setting (LOD care units) cannot be completely generalized to another (YOD SCUs).

Despite adding a tool to the intervention for monitoring PDU, no significant decrease in PDU after implementation of the intervention was found. A possible explanation could be that the current policy that favors limiting the prescription of psychotropic drugs has already positively influenced the prescription pattern to some degree, leaving less room for improvement. Indeed, when comparing the PDU rates in our study (68.6\% using at least one drug) with the rates in $\mathrm{NH}$ residents with YOD approximately 10 years ago (87.6\% using at least one drug), the rates in our study appear considerably lower. ${ }^{4}$

Our results suggest that after working longer with the intervention, it became more effective in decreasing delusions. However, not even a trend toward increasing or decreasing effectiveness was found for other NPS. Therefore, we expected that this interaction effect might have been a result of multiple testing.

An important strength of this study was that we were able to include a large sample size of $\mathrm{NH}$ residents, resulting in sufficient study power $(80 \%$ for an effect of $0.4 \times$ standard deviation). ${ }^{23}$ This is an advantage, especially in research on YOD, because the prevalence of $\mathrm{NH}$ residents with YOD is much lower compared with LOD. Some limitations of this study should also be considered. The presence of NPS was based on the observations of nurses who could not be blinded. Awareness of being in the intervention or control condition might have influenced their ratings to some degree. Furthermore, no assessment instruments are available that take into account the specific characteristics of younger individuals with dementia.
Therefore, we chose to measure NPS with assessment instruments designed and validated for use in $\mathrm{NH}$ residents with LOD. ${ }^{36,38}$ However, the CMAI does not extensively assess behavior associated with frontal lobe dysfunction, which might be more likely to occur in younger $\mathrm{NH}$ residents with dementia because of the higher prevalence of frontotemporal dementia. ${ }^{1}$ Finally, we decided not to include as needed medications in the effect analysis because in our study we did not collect data on how often these drugs were actually used. Therefore, we could not establish the influence of the intervention on the admission of medication as needed.

\section{CONCLUSION}

We found no evidence that the intervention was more effective in reducing agitation, aggression, other NPS, or PDU compared with care as usual. The perceived overlap between the intervention and current working methods and lower PDU rates compared with approximately 10 years ago suggests that YOD SCUs had already (to some degree) developed effective working methods for structuring the management of NPS in YOD before implementation of our intervention, diminishing the intervention effect. In future studies, more research on the specific needs and context of YOD SCUs during the development phase of an intervention is important to improve the relevance and effectiveness of the intervention in this specific context.

This study was funded by the Netherlands Organization for Health Research and Development (nr: 733050402), the Archipel Care Group in the Netherlands, the Florence Care Group in the Netherlands, the Dutch YOD Knowledge Center, and the Dutch Alzheimer Society. The authors have no conflicts of interest to declare.

\section{References}

1. Mulders AJ, Zuidema SU, Verhey FR, et al: Characteristics of institutionalized young onset dementia patients-the BEYOnD study. Int Psychogeriatr 2014; 12:1973-1981

2. Murman DL: The incremental direct costs associated with behavioral symptoms in AD. Neurology 2002; 59:1721-1729

3. Wetzels R, Zuidema S, de Jonghe J, et al: Determinants of quality of life in nursing home residents with dementia. Dement Geriatr Cogn Disord 2010; 29:189-197
4. Mulders AJ, Fick IW, Bor H, et al: Prevalence and correlates of neuropsychiatric symptoms in nursing home patients with young-onset dementia: the BEYOnD study. J Am Med Dir Assoc 2016; 17:495-500

5. Zwijsen SA, Kabboord A, Eefsting JA, et al: Nurses in distress? An explorative study into the relation between distress and individual neuropsychiatric symptoms of people with dementia in nursing homes. Int J Geriatr Psychiatry 2014; 29:384-391 
6. Appelhof B, Bakker C, van Duinen-van den IJssel JC, et al: The determinants of quality of life of nursing home residents with young-onset dementia and the differences between dementia subtypes. Dement Geriatr Cogn Disord 2017; 43:320-329

7. van Duinen-van den IJssel JC, Mulders AJ, Smalbrugge M, et al: Nursing staff distress associated with neuropsychiatric symptoms in young-onset dementia and late-onset dementia. J Am Med Dir Assoc 2018; 19:627-632

8. Gerritsen AJ, Bakker C, Verhey RJ, et al: Prevalence of comorbidity in patients with young-onset Alzheimer disease compared with late-onset: a comparative cohort study. J Am Med Dir Assoc 2016; 17:318-323

9. Appelhof B, Bakker C, van Duinen-van den IJssel JC, et al: Differences in neuropsychiatric symptoms between nursing home residents with young-onset dementia and late-onset dementia [published online ahead of print February 9, 2018]. Aging Ment Health. doi: 10.1080/13607863.2018.1428935

10. Wetzels RB, Zuidema SU, de Jonghe JF, et al: Prescribing pattern of psychotropic drugs in nursing home residents with dementia. Int Psychogeriatr 2011; 23:1249-1259

11. Ballard C, Howard R: Neuroleptic drugs in dementia: benefits and harm. Nat Rev Neurosci 2006; 7:492-500

12. Schneider LS, Dagerman K, Insel PS: Efficacy and adverse effects of atypical antipsychotics for dementia: meta-analysis of randomized, placebo-controlled trials. Am J Geriatr Psychiatry 2006; 14:191-210

13. Cohen-Mansfield JJ: Nonpharmacologic interventions for inappropriate behaviors in dementia: a review, summary, and critique. Am J Geriatr Psychiatry 2001; 9:361-381

14. Cohen-Mansfield J, Billig N: Agitated behaviors in the elderly. I. A conceptual review. J Am Geriatr Soc 1986; 34:711-721

15. Cohen-Mansfield J: Heterogeneity in dementia: challenges and opportunities. Alzheimer Dis Assoc Disord 2000; 14:60-63

16. Bakker C, de Vugt ME, van Vliet D, et al: The relationship between unmet care needs in young-onset dementia and the course of neuropsychiatric symptomps: a two year follow-up study. Int Psychogeriatr 2014; 26:1991-2000

17. Kovach CR, Noonan PE, Schlidt AM, et al: A model of consequences of need-driven, dementia-compromised behavior. J Nurs Scholarsh 2005; 37:134-140, discussion 140

18. Edvardsson D, Winblad B, Sandman PO: Person-centred care of people with severe Alzheimer's disease: current status and ways forward. Lancet Neurol 2008; 7:362-367

19. Zwijsen SA, Smalbrugge M, Zuidema SU, et al: Grip on challenging behaviour: a multidisciplinary care programme for managing behavioural problems in nursing home residents with dementia. Study protocol. BMC Health Serv Res 2011; 11:41

20. Zwijsen SA, Gerritsen DL, Eefsting JA, et al: The development of the grip on challenging behaviour dementia care programme. Int J Palliat Nurs 2014; 20:15-21

21. Zwijsen SA, Smalbrugge M, Eefsting JA, et al: Coming to grips with challenging behavior: a cluster randomized controlled trial on the effects of a multidisciplinary care program for challenging behavior in dementia. J Am Med Dir Assoc 2014; 15:531.e1-531.e10

22. Zwijsen SA, Gerritsen DL, Eefsting JA, et al: Coming to grips with challenging behaviour: a cluster randomised controlled trial on the effects of a new care programme for challenging behaviour on burnout, job satisfaction and job demands of care staff on dementia special care units. Int J Nurs Stud 2015; 52:68-74

23. van Duinen-van den IJssel JC, Appelhof B, Zwijsen SA, et al: Behavior and Evolution of Young-ONset Dementia Part 2 (BEYOND-II) study: an intervention study aimed at the improvement of the management of challenging behavior in institutionalized people with young-onset dementia. Int Psychogeriatr 2017;30(3):437-446;doi:10.1017/\$1041610217000941

24. Appelhof B, Bakker C, van Duinen-van den IJssel JC, et al: Process evaluation of an intervention for the management of neuropsychiatric symptoms in institutionalized people with young-onset dementia: the Beyond-II study. J Am Med Dir Assoc 2018;19 (8):663-671;doi:10.1016/j.jamda.2018.02.013

25. Leontjevas R, Gerritsen DL, Koopmans RT, et al: Process evaluation to explore internal and external validity of the "Act in Case of Depression" care program in nursing homes. J Am Med Dir Assoc 2012; 13:488.e1-488.e8

26. American Psychiatric Association. Diagnostic and Statistical Manual of Mental Disorders. 4th ed Washington, DC: American Psychiatric Association, 2000 Text Revision

27. Gorno-Tempini ML, Hillis AE, Weintraub S, et al: Classification of primary progressive aphasia and its variants. Neurology 2011; 76:1006-1014

28. McKeith IG: Consensus guidelines for the clinical and pathologic diagnosis of dementia with Lewy bodies (DLB): report of the Consortium on DLB International Workshop. J Alzheimers Dis 2006;9(suppl 3):417-423

29. McKhann GD, Drachman D, Folstein M, et al: Clinical diagnosis of Alzheimer's disease: report of the NINCDS-ADRDA Work Group under the auspices of Department of Health and Human Services Task Force on Alzheimer's Disease. Neurology 1984; 34:939-944

30. Rascovsky K, Hodges JR, Knopman D, et al: Sensitivity of revised diagnostic criteria for the behavioural variant of frontotemporal dementia. Brain 2011;134(pt 9):2456-2477

31. Roman GC, Tatemichi TK, Erkinjuntti T, et al: Vascular dementia: diagnostic criteria for research studies. Report of the NINDSAIREN International Workshop. Neurology 1993; 43:250-260

32. van der Spek K, Gerritsen DL, Smalbrugge M, et al: A reliable and valid index was developed to measure appropriate psychotropic drug use in dementia. J Clin Epidemiol 2015; 68:903-912

33. van der Spek K, Gerritsen DL, Smalbrugge M, et al: PROPER I: frequency and appropriateness of psychotropic drugs use in nursing home patients and its associations: a study protocol. BMC Psychiatry 2013; 13:307

34. Orrell M, Hancock G: CANE: Camberwell Assessment of Need for the Elderly. London: Gaskell, 2004

35. Brown CA, Lilford RJ: The stepped wedge trial design: a systematic review. BMC Med Res Methodol 2006; 6:54

36. de Jonghe JF, Kat MG: Factor structure and validity of the Dutch version of the Cohen Mansfield Agitation Inventory (CMAI-D). J Am Geriatr Soc 1996; 44:888-889

37. Zuidema SU, de Jonghe JF, Verhey FR, et al: Agitation in Dutch institutionalized patients with dementia: factor analysis of the Dutch version of the Cohen-Mansfield Agitation Inventory. Dement Geriatr Cogn Disord 2007; 23:35-41

38. Wood S, Cummings JL, Hsu MA, et al: The use of the Neuropsychiatric Inventory in nursing home residents. Characterization and measurement. Am J Geriatr Psychiatry 2000; 8:75-83

39. Zuidema SU, Derksen E, Verhey FR, et al: Prevalence of neuropsychiatric symptoms in a large sample of Dutch nursing home patients with dementia. Int J Geriatr Psychiatry 2007; 22:632-638

40. World Health Organization. Anatomical Therapeutic Chemical (ATC) Classification Index Including Defined Daily Doses (DDDs) for Plain Substances. Oslo: World Health Organisation Collaborating Centre for Drug Statistics Methodology, 1997

41. Reisberg B, Ferris SH, de Leon MJ, et al: The Global Deterioration Scale for assessment of primary degenerative dementia. Am J Psychiatry $1982 ; 139: 1136-1139$ 